\title{
Atitudes do locutor no discurso por meio da conversão entre aspectos argumentativos
}

\author{
Speaker's attitude in the discourse by conversion between argumentative aspects \\ Cláudio Primo Delanoy \\ Pontifícia Universidade Católica do Rio Grande do Sul - Porto Alegre - Rio Grande do Sul - Brasil
}

$\diamond$

\begin{abstract}
Resumo: Com este artigo objetivamos descrever e explicar as atitudes tomadas pelo locutor ao expressar seu ponto de vista frente a outro(s) discurso(s), bem como investigar as relações entre esses discursos e seus sentidos, sob o enfoque da Teoria da Argumentação na Língua e da Teoria dos Blocos Semânticos. Escolhemos a relação entre os discursos do tipo A portanto $B$ e $A$ no entanto não- $B$, denominados encadeamentos argumentativos conversos entre si. Elegemos essa fundamentação teórica porque se trata de uma proposta semântica de análise da linguagem pela qual o sentido é construído pela relação estabelecida entre palavras, frases e parágrafos, em uma situação enunciativa. O corpus considerado para a análise é uma crônica. Após a análise das argumentações, os aspectos argumentativos assumidos pelos locutores podem ser relacionados entre si e assim permitem um estudo a respeito do sentido que constroem e das atitudes dos locutores ali envolvidos.
\end{abstract}

Palavras-chave: Teoria da Argumentação na Língua; Teoria dos Blocos Semânticos; Atitudes do locutor; Discurso

\begin{abstract}
The goal of this paper is to describe and explain the actions taken by the speaker to express his point of view in relation to others discourses, and to investigate the relation among these discourses and their meanings, under the perspective of the Theory of Argumentation within Language and the Theory of Semantic Blocks. We chose the relation between discourses $A$ threrefore $B$ and $A$ however not- $B$ denominated argumentative chains in conversion. We elected these theories because they consider that the meaning is built by language in the relation established among words, sentences and paragraphs, in a situation of enunciation. The corpus considered for analysis consists of a chronicle. After the argumentation analysis, the argumentative aspects can be related to each other and thus it allows us to study the meaning built by the speakers and their attitudes.
\end{abstract}

Keywords: Theory of Argumentation within Language; Theory of Semantic Blocks; Speaker's attitude; Discourse

\section{Introdução}

O estudo do sentido produzido pelo discurso não pode desconsiderar o uso da linguagem. Por uso da linguagem, entendemos a sua produção por um locutor, para um interlocutor, em um tempo e espaço determinados, caracterizando a natureza enunciativa do discurso. Nesse ambiente de interação, que é a linguagem, o locutor expressa discursivamente uma visão a respeito de um tema e entra em relação com outros locutores, ou, melhor dizendo, com outros discursos. Levando em conta essa perspectiva, com este trabalho pretendemos descrever e explicar as atitudes tomadas pelo locutor ao expressar seu ponto de vista frente a outro(s) discurso(s), bem como investigar as relações entre esses discursos e seus sentidos ali construídos, sob o viés da Teoria da Argumentação na Língua, de Oswald Ducrot e Jean-Claude Anscombre, e da Teoria dos Blocos Semânticos, de Marion Carel e Oswald Ducrot. Escolhemos a relação entre os discursos do tipo $A$ portanto $B$ e $A$ no entanto não- $B$, denominados encadeamentos argumentativos conversos entre si, segundo nossa fundamentação teórica adotada.

Elegemos a Teoria da Argumentação na Língua e a Teoria dos Blocos Semânticos (ADL, do francês Argumentation Dans la Langue/ TBS, Théorie des Blocs Sémantiques) porque se trata de uma proposta semântica 
de análise da linguagem que entende ser o sentido construído pela relação estabelecida entre palavras, frases e parágrafos, em uma situação enunciativa. A ADL/TBS parte do pressuposto de que o sentido é construído pela linguagem. Além disso, é na linguagem que o locutor expressa sua subjetividade. Como teoria enunciativa, afirma que o locutor constrói um enunciado cujo sentido é a representação de sua enunciação. Desse modo, o sentido é de responsabilidade do locutor que, ao produzir linguagem, toma posição diante dos fatos sobre os quais se enuncia.

De acordo com a TBS, ao locutor apresentam-se oito maneiras de expressar um ponto de vista, correspondentes a oito aspectos argumentativos. Esses aspectos traduzem o sentido de uma argumentação por meio de dois segmentos ligados por um conector, sob a forma A CON B. Essa forma representa, então, uma argumentação. O primeiro segmento (A) é chamado suporte e o segundo (B), aporte. O conector $(\mathrm{CON})$ pode ser de dois tipos: DC, do francês donc, que pode ser traduzido por portanto, e PT, vindo de pourtant, com sentido de no entanto. Os aspectos argumentativos relacionam-se entre si por meio da alternância do conector (DC e PT) e da presença (ou não) da negação nos segmentos. Essas argumentações são representativas de um bloco semântico, que é o sentido construído pela interdependência semântica entre os dois segmentos de uma argumentação. Os aspectos argumentativos de um bloco semântico relacionam-se em pares e recebem nomes específicos: conversão, reciprocidade e transposição. Para este trabalho, estudamos a conversão, representada pelos aspectos A DC B e A PT neg-B, que representa a negação de uma argumentação.

A nossa proposta é que o locutor, ao expressar um ponto de vista, assume um determinado aspecto argumentativo de um bloco semântico. Ao entrar em contato com outro discurso, que também é representado por um aspecto argumentativo, o locutor toma uma atitude. Esse debate entre discursos se dá por meio de uma das relações possíveis entre os aspectos argumentativos. Assim, nossa meta é descrever e explicar essas atitudes do locutor por meio da relação de conversão entre os aspectos.

A metodologia do trabalho envolveu pesquisas em conceitos da ADL, notadamente na sua versão da TBS, para possibilitar a descrição e a explicação das relações interdiscursivas conversas e das atitudes do locutor. O corpus foi constituído de uma crônica, selecionada por apresentar relações de conversão entre discursos. Após a descrição semântica dessas argumentações, os aspectos argumentativos assumidos pelos locutores podem ser relacionados entre si e assim permitem o estudo a respeito do sentido que constroem e das atitudes dos locutores ali envolvidos.

Com a finalidade de orientar nossa pesquisa, elencamos os seguintes objetivos: (i) Descrever o sentido dos discursos por meio de aspectos argumentativos; (ii) Descrever e explicar a relação de conversão entre discursos; e (iii) Analisar as atitudes do locutor quando responde a um discurso do tipo $A$ portanto $B$ com o seu converso $A$ no entanto não- $B$. A partir desses objetivos, temos como perguntas norteadoras: (i) Que sentidos constroem no discurso os pontos de vista ou aspectos argumentativos escolhidos pelo locutor?; (ii) O que significa a conversão entre aspectos argumentativos?; e (iii) Que atitudes argumentativas o locutor pode assumir no discurso ao argumentar pela conversão entre aspectos?

O trabalho está estruturado da seguinte maneira: primeiramente apresentamos a argumentação linguística nos moldes da ADL/TBS, confrontada com a argumentação retórica. A seguir, apresentamos as bases da ADL: os vínculos a Saussure e à enunciação, como também respondemos ao porquê de a argumentação estar na língua, tal como propõe a ADL. Na terceira parte, como fechamento da fundamentação teórica, discorremos sobre os conceitos básicos da TBS, bem como detalhamos as relações entre os aspectos argumentativos, sobretudo a conversão. Por fim, analisamos uma crônica de Luis Fernando Verissimo, $O$ líder natural, com vistas a descrevermos os pontos de vista dos locutores, ou seja, suas argumentações, e suas relações com outros discursos. Pretendemos, dessa forma, chegar às atitudes do locutor frente a esses outros discursos.

\section{A argumentação linguística}

Oswald Ducrot, no artigo Argumentação retórica e argumentação linguística (DUCROT, 2009, p. 20), define dois sentidos para a palavra argumentação. Conforme o título do seu artigo, concebe uma argumentação retórica e outra linguística. Escreve:

Efetivamente, eu não só distinguirei os fenômenos que entram nessas acepções da palavra argumentação (o que é apenas um trabalho de terminologia), mas também as oporei, mostrando que a argumentação linguística não tem nenhuma relação direta com a argumentação retórica. (DUCROT, 2009, p. 20).

O conceito mais elementar de argumentação diz respeito a modos de induzir o outro a adotar um posicionamento sobre um tema. A argumentação retórica, por Ducrot (2009) é: “[...] a atividade verbal que visa fazer alguém crer em alguma coisa." (DUCROT, 2009, p. 20). Em contraponto, Ducrot conceitua argumentação linguística:

[...] chamarei assim os segmentos de discurso constituídos pelo encadeamento de duas proposições A e C, ligadas implícita ou explicitamente por um conector do tipo donc (portanto), alors (então), par conséquent (consequentemente)... (DUCROT, 2009, p. 20-21, grifos do autor). 
Em nota de rodapé (DUCROT, 2009, p. 20), o autor explica que, no momento recente da Teoria da Argumentação na Língua - a Teoria dos Blocos Semânticos, também são consideradas argumentações os encadeamentos em pourtant (no entanto), mas que esse tópico não seria desenvolvido em seu artigo porque se tratava de uma comparação com a argumentação retórica, e por isso não mencionaria as argumentações em pourtant.

Dando prosseguimento à sua reflexão, Ducrot parte do princípio de que argumento e conclusão (proposições A e C), encadeados sob a forma $A$ portanto $C$, geralmente são tomados como se $\mathrm{A}$ justificasse $\mathrm{C}$ e como se $\mathrm{C}$ ganhasse sua validade ao ser articulado a $\mathrm{A}$.

Pela retórica, um argumento A leva a uma conclusão $\mathrm{C}$ a partir dele mesmo, apoiado em um topos, ou lugarcomum argumentativo, que garantiria a passagem de A a C. Por exemplo, na proposição aquele aluno é muito inteligente, é certo que será um bom profissional, o argumento aquele aluno é muito inteligente, combinado ao senso comum de que pessoas inteligentes são bons profissionais, levaria àquela conclusão. Inclusive o argumento é concebido como uma justificação da conclusão, como se o fato de ser inteligente justificasse a previsão de o aluno vir a ser bom profissional. Argumento e conclusão seriam entidades individuais, fechadas semanticamente em si mesmas, mas ligadas por um topos.

Na visão de Ducrot (2009), argumento e conclusão são inseparáveis semanticamente. Além disso, apesar de comumente ser aceito um sentido de justificação presente na argumentação, pela perspectiva de Ducrot essa presença é ilusória (DUCROT, 2009, p. 21). Não há caráter justificativo na argumentação, embora essa interpretação faça parte do conhecimento dos sujeitos falantes. Recorremos mais uma vez ao linguista:

A ideia de base é que, num encadeamento argumentativo $A$ donc (portanto) $C$, o sentido do argumento A contém em si mesmo a indicação de que ele deve ser completado pela conclusão. Assim, o sentido de A não pode ser definido independentemente do fato de que Aé visto como conduzindo a C. Não há, pois, propriamente falando, passagem de $\mathrm{A}$ a $\mathrm{C}$, não há justificação de $\mathrm{C}$ para um enunciado $\mathrm{A}$ que seria compreensível em si mesmo, independentemente da sequência portanto $C$. Consequentemente, não há transporte de verdade, transporte de aceitabilidade, de A até $\mathrm{C}$, já que o encadeamento apresenta portanto $C$ como já incluído no primeiro termo A. (DUCROT, 2009, p. 22).

Um exemplo dado por Ducrot (2009) esclarece a citação. Tomemos os seguintes encadeamentos (em ambos portanto está implícito): (i) Tu diriges depressa demais, tu corres o risco de sofrer um acidente;

(ii) Tu diriges depressa demais, tu corres o risco de cometer uma infração.

Esses enunciados poderiam ser explicados no sentido de a conclusão tu corres o risco de sofrer um acidente, por exemplo, decorrer de um raciocínio fundamentado num lugar-comum (topos) de que a velocidade excessiva pode causar acidentes. Porém isso não se aplica, pois o argumento $T u$ diriges depressa demais não tem sentido completo em si, ele não justifica a conclusão, porque seu sentido depende dela. Observamos que tanto em (i) como em (ii) a expressão depressa demais assume sentidos distintos, sentidos decorrentes de sua interdependência semântica com a conclusão. Em (i) depressa demais significa uma velocidade perigosa, capaz de gerar acidentes, ao passo que em (ii) a expressão significa uma velocidade que provoca uma infração. Então, pela explicação de Ducrot, não há um argumento autossuficiente semanticamente que justifique a conclusão apoiado em princípios argumentativos. Há sim uma interdependência de sentido entre $\mathrm{A}$ e $\mathrm{C}$, ambos concorrentes na produção do sentido do encadeamento.

Até aqui, discutimos distintas concepções de argumentação e procuramos distingui-las. A partir deste ponto, adotamos a argumentação tal como foi definida por Ducrot e Carel, no âmbito da ADL. Argumentar é colocar em relação duas proposições, ou dois segmentos, que assumirão um sentido construído justamente por essa relação. E o responsável pela construção desses encadeamentos em uma situação discursiva é o locutor. Por isso, dizemos também que argumentar é apresentar um ponto de vista sobre algo, ou seja, quando o locutor se posiciona a respeito de um assunto, ele está argumentando. Seguindo nosso percurso teórico, até aqui respondemos o que é argumentação. Na continuidade, desenvolveremos os fundamentos da ADL e o porquê de a argumentação estar na língua.

\section{A Teoria da Argumentação na Língua}

A ADL tem suas raízes nos princípios saussurianos, como a definição de signo linguístico, a noção de valor do signo, os conceitos de língua/fala e as relações sintagmáticas e paradigmáticas.

A esse respeito, escreve Ducrot:

Em termos gerais, pode afirmar-se que a ADL é uma aplicação do estruturalismo saussuriano à semântica linguística na medida em que, para Saussure, o significado de uma expressão reside nas relações dessa expressão com outras expressões da língua. (CAREL; DUCROT, 2005, p. 11, tradução nossa). 
Para a $\mathrm{ADL}$, somente ao entrarem em relação, isto é, no discurso, é que as palavras produzem sentido, ou, como escreve Saussure na Nota sobre o discurso, são capazes de expressar "significação de pensamento" (SAUSSURE, 2004, p. 237). Fora do uso, quer dizer, no sistema da língua, as palavras têm conceitos isolados que, pelas palavras do linguista, "esperam ser postos em relação entre si para que haja significação de pensamento." (SAUSSURE, 2004, p. 237).

É devido a essa interdependência semântica que a ADL afirma ser o sentido argumentativo, quer dizer, o sentido de uma expressão depende da continuação que lhe é dada. É também pela noção de relação e pela sua importância na construção do sentido que se confirma o vínculo de Ducrot a Saussure.

Ducrot (1984, p. 368) afirma ser necessário identificar dois elementos distintos na produção de uma sequência de palavras. Um deles é o material linguístico empregado, pertencente ao sistema da língua e, portanto, de caráter abstrato. Outro são as diversas realizações desse material, que dizem respeito a uma pessoa (no sentido gramatical), num determinado espaço e tempo. A partir dessa distinção, Ducrot define uma terminologia que irá usar no desenvolvimento de sua teoria linguística, conceituando frase, texto, enunciado e discurso. Frase é o material linguístico usado pelo locutor, é um construto teórico, enquanto texto designa um conjunto de frases, ambos abstratos. Enunciado é a realização da frase, objeto construído, ou seja, o que foi efetivamente pronunciado ou escrito; e discurso é um conjunto de enunciados ligados entre si, o que resulta ser a concretização de um texto.

Ducrot distingue os valores semânticos da frase e do enunciado. As frases são dotadas de significação e os enunciados têm sentido. O linguista separa significação de sentido por considerar que esse último somente é produzido no uso, não havendo a ideia de sentido constante. A significação, por outro lado, é constituída de instruções abertas, isto é, não preconcebidas, que vão produzir sentido no uso da língua. Por exemplo, a conjunção mas (chamada de articulador, por Ducrot) teria uma instrução como "busque no enunciado um argumento que deve ser contrário a outro, e tire uma conclusão a partir do segundo". Com isso, vemos que, para se chegar ao sentido, precisamos da significação (das instruções), e vice-versa. Sentido e significação são, então, interdependentes.

Para o linguista, língua e fala são inseparáveis. O sistema, correspondente a frase para a ADL, necessita do uso para que o sentido seja completado. Logo, é no uso da língua que os falantes encontram o sentido do enunciado.

Para Ducrot, a aplicação das relações sintagmáticas está na noção de encadeamento argumentativo. Segundo a TBS, a relação não se dá entre argumento e conclusão, mas entre dois segmentos articulados por um conector, segmentos esses interdependentes semanticamente. Inclusive, em Carel e Ducrot (2008, p. 10) encontramos: "Dar o significado de uma expressão é associar-lhe diferentes argumentações que são evocadas por seu emprego", marcando claramente que ambos segmentos são dependentes entre si para a construção do sentido.

As relações paradigmáticas, no âmbito da ADL/TBS, podem ser exemplificadas por meio de encadeamentos possíveis de serem construídos a partir da orientação argumentativa do léxico. Desse modo, o prosseguimento de João é inteligente, portanto... seria concluído de forma positiva, como vai conseguir o emprego, vai solucionar o problema ou vai ser aprovado. Essa positividade deve-se à orientação argumentativa presente no interior de inteligente, que conduz a continuação do enunciado a uma conclusão dessa qualidade. Assim, as diversas sequências admissíveis a João é inteligente, portanto... formam um paradigma, a partir do qual uma continuação será selecionada pelo locutor. Conforme salientamos no parágrafo anterior, a escolha do segundo segmento influenciará semanticamente o primeiro, assim como o primeiro segmento já traz em si uma orientação para o segundo. Assim: ao dizermos João é inteligente, portanto vai conseguir o emprego construímos um sentido de inteligência para ser aprovado num processo seletivo de emprego, ao passo que em João é inteligente, portanto vai solucionar o problema o sentido será de inteligência própria para a resolução de problemas. Ora, a inteligência que propicia ser selecionado em um concurso não é a mesma, ou não tem o mesmo sentido, daquela que dá aptidão para a solução de problemas. Pretendemos, então, por essa exemplificação, mostrar a influência semântica mútua de um segmento sobre o outro para a formação do sentido, que a TBS chamará de bloco semântico.

A ADL é considerada uma teoria enunciativa. Prevê um locutor produzindo um enunciado (ou discurso) a um interlocutor. O locutor é o ser responsável pelo enunciado e no qual se marca ao produzir eu, aqui e agora. $\mathrm{O}$ interlocutor é o destinatário do enunciado. Locutor e interlocutor são seres discursivos, abstratos, e não devem ser confundidos com seres reais. Essa distinção é defendida por Ducrot porque seu foco é a argumentação produzida no sistema linguístico e pelo próprio sistema, enquanto o indivíduo real pertenceria ao mundo extralinguístico, do qual o linguista não se ocupa.

Ducrot denomina enunciação ao surgimento do enunciado. Esse conceito não deve ser confundido com a enunciação para Benveniste. Há uma distinção de objeto de estudo: Benveniste se ocupou do processo de construção do enunciado, do ato em si. Ducrot, por outro lado, tem 
como objeto o enunciado, o produto da enunciação, e assim precisava de um aparato teórico que desse conta da sua investigação. Também afirma que o sentido do enunciado é a descrição da sua enunciação (DUCROT, 1987, p. 172). Pelo que foi visto, compreende-se a preocupação de Ducrot ao embasar a ADL numa fundamentação teórica sólida que the desse respaldo suficiente para estudar o sentido conforme a sua perspectiva: construído na língua. A base na concepção saussuriana, mesmo modificada em alguns aspectos, contribuiu para a investigação da língua referentemente às suas relações internas, sem alusão referencial ao mundo extralinguístico para a produção do sentido. Ao estudar o sentido produzido na língua, Ducrot não poderia desconsiderar o uso da língua.

\section{Por que argumentação na língua?}

A definição de argumentação também é normalmente vinculada à ideia de ter apoio nos fatos do mundo, como se uma conclusão $C$ fosse resultado de uma inferência a partir de um fato $\mathrm{F}$ - denominada de concepção ingênua, segundo Ducrot (1990, p. 75). Assim, um argumento A indicaria o fato $F$, que, por sua vez, implicaria a conclusão C. O argumento A seria uma representação da realidade que poderia ser considerada verdadeira ou falsa, independentemente da conclusão feita a partir dela. Ainda, nessa perspectiva, F e $\mathrm{C}$ estariam conectados por razões lógicas, ou psicológicas, ou por motivos sociológicos, ou pelo conhecimento de mundo, mas em nada vinculado à língua em si. A língua serviria, então, como instrumento para o elo entre $\mathrm{F}$ e $\mathrm{C}$, como uma passagem. Sua contribuição para a argumentação, assim, seria bem restrita.

A oposição que Ducrot (1990) faz relativamente a essa perspectiva "ingênua" reside na possibilidade dada pela língua de designar, por meio de expressões linguísticas distintas, o mesmo fato $\mathrm{F}$ no mundo. Além disso, essas expressões distintas permitem construir argumentações também diferentes, mesmo referindo-se a F. Vejamos um exemplo. Imaginemos uma situação na qual faltam alguns minutos para as $21 \mathrm{~h}$, hora do início de uma peça teatral. Podemos enunciar são quase $21 \mathrm{~h}$ ou não são ainda $21 \mathrm{~h}$, dependendo de como quisermos continuar nossa fala. Se escolhermos são quase $21 \mathrm{~h}$ teremos como continuação expressões que indiquem a necessidade de apressar-se, visto a iminência de começar o espetáculo, como não vamos perder tempo; ou vamos chamar logo o táxi. Por outro lado, se dissermos não são ainda $21 h$, a orientação do discurso apontará para a não necessidade de ter pressa, e teremos possíveis continuações como temos tempo ou podemos caminhar até o teatro. O tempo que separa o momento da enunciação até as $21 \mathrm{~h}$ é o mesmo, tanto em um quanto no outro exemplo. A diferença está no modo de o locutor avaliar esse espaço de tempo, e o fará pela linguagem, com vistas a argumentar. Logo, a representação do mundo se dá por uma descrição argumentativa da realidade, feita pelo locutor. $\mathrm{O}$ locutor não tem como apreender a realidade senão pela linguagem, e nessa apreensão, expressa sua subjetividade, sua interpretação da circunstância. Assim, ele argumenta.

Outra razão pela qual Ducrot (1990) se opõe à concepção tradicional de sentido é o conceito de valor argumentativo. Afirma: "O valor argumentativo de uma palavra é, por definição, a orientação que essa palavra dá ao discurso." (DUCROT, 1990, p. 51, tradução nossa). Quer dizer que as expressões linguísticas, e aqui incluímos também enunciados e não só palavras, trazem em si possibilidades de continuação do discurso, ao mesmo tempo que impedem outras. $\mathrm{O}$ valor argumentativo de uma expressão é, então, o conjunto dessas possibilidades, ou impossibilidades, de continuação discursiva. O exemplo Maria é uma profissional competente pode orientar para então terá êxito no novo projeto, ou portanto não há com o que se preocupar, etc. Percebemos uma continuação de certa forma positiva a partir do enunciado. Tanto parece ser assim que, caso o locutor prossiga o discurso com não tem tempo para abraçar novas atividades, terá de marcar essa mudança de orientação com mas, contudo, porém, etc.

São constatações desse tipo que levaram Ducrot a sustentar que a argumentação está na língua, é prevista por ela. Em Ducrot (1989, p. 18) há que "[...] a significação de certas frases contém instruções que determinam a intenção argumentativa a ser atribuída a seus enunciados: a frase indica como se pode, e como não se pode argumentar a partir de seus enunciados." (DUCROT, 1989, p. 18). Assim, o conceito de orientação argumentativa presente nas palavras permitiu Ducrot afirmar que a argumentação está no sistema da língua.

Na finalização desta parte, respondemos por que argumentação na língua. Vimos que, basicamente, a argumentação estava vinculada a representações da realidade e que a língua em si tomava um papel restrito, de intermediária entre os fatos e as conclusões. De maneira contrária, Ducrot localiza a argumentação no próprio sistema linguístico, ao afirmar que as expressões da língua carregam em si uma orientação argumentativa para a continuação do discurso, independentemente da representação que possam fazer da realidade, e que o sentido de uma entidade linguística é dado pela relação entre uma expressão e outras expressões que a seguem. Logo, a argumentação não está nos fatos do mundo, mas está na natureza da língua. Os conceitos da ADL apresentados até aqui são fundamentais para a fase recente deste corpo teórico: a Teoria dos Blocos Semânticos. 


\section{A Teoria dos Blocos Semânticos}

A TBS teve seu início em 1992 com a tese de Marion Carel, que trouxe contribuições para a consolidação da $\mathrm{ADL}$, principalmente no que concerne à manutenção do seu vínculo com a proposta saussuriana. A TBS propõe uma nova concepção de sentido: "A ideia central da teoria é que o sentido mesmo de uma expressão é dado pelos discursos argumentativos que podem encadear-se a partir dessa expressão." (CAREL; DUCROT, 2005, p. 13, tradução nossa). Dessa maneira, o sentido não é mais constituído por propriedades psicológicas, ideias, crenças, mas por discursos que a entidade linguística evoca, denominados encadeamentos argumentativos (CAREL; DUCROT, 2005, p. 14). Ficou garantida, então, a coerência da ADL com sua base saussuriana de estudar um objeto através de suas relações internas. A unidade mínima de sentido, no âmbito da TBS, é uma relação entre dois segmentos e um conector, ou seja, um encadeamento argumentativo ou argumentação: "Para nós, as relações entre signos que estão na base de todo significado, e que são como átomos da significação, são o que chamamos 'encadeamentos argumentativos' ou ainda 'argumentações'." (CAREL; DUCROT, 2008, p. 9). Uma argumentação, então, é formada por uma sequência ACON B, em que A é o segmento suporte (o antecedente, anterior) e B é o segmento aporte (o consequente, posterior). Carel e Ducrot $(2008$, p. 9) alertam que os segmentos suporte e aporte não são determinados simplesmente pela posição que ocupam no enunciado, mas pela função exercida em relação ao outro segmento. De maneira que o segmento está chovendo será suporte tanto em está chovendo, no entanto vou sair, quanto em vou sair, mesmo que esteja chovendo.

Para explicarmos o que é um bloco semântico, retomamos os seguintes enunciados:

(i) Tu diriges depressa demais, (portanto) corres o risco de sofrer um acidente;

(ii) Tu diriges depressa demais, (portanto) corres o risco de cometer uma infração.

Conforme explicamos anteriormente, os enunciados acima constroem sentidos distintos devido à interdependência semântica entre o suporte e o aporte de cada argumentação. Em (i), temos o sentido de velocidade perigosa, ao passo que em (ii) trata-se de uma velocidade proibida. O conceito de bloco semântico decorre justamente dessa interdependência entre os segmentos. Logo, em (i) e em (ii) temos exemplos de dois blocos semânticos distintos, um que articula o excesso de velocidade a sofrer acidentes e outro a cometer infração. O bloco se constrói, portanto, nessa interdependência de sentidos entre os segmentos. Portanto, a relação entre os segmentos é fundamental para a constituição do sentido.

Os blocos semânticos são representados por encadeamentos argumentativos. Na formação dos encadeamentos, os segmentos são ligados por conectores do tipo donc, do francês, simbolizado por DC e que pode ser traduzido por portanto, formando um encadeamento normativo; e pourtant, simbolizado por PT, no entanto, constituindo um encadeamento transgressivo (CAREL; DUCROT, 2005, p. 14). Os conectores DC e PT são metalinguísticos, são representativos de outras expressões linguísticas. Assim, DC pode desempenhar o papel de outras expressões além de portanto, como, por exemplo: se João é prudente, então não sofrerá nenhum acidente. Do mesmo modo, o conector PT também está presente, dentre outras possibilidades, como: mesmo João sendo prudente, sofreu um acidente.

$\mathrm{O}$ encadeamento normativo em portanto (DC) é a afirmação da norma e o transgressivo em no entanto (PT), a sua negação. Acrescentamos ainda que os encadeamentos em PT, além de negarem o aspecto normativo, expressam o reconhecimento da existência de exceções à norma estabelecida por DC, e por isso a transgridem. Chamamos a atenção para o fato de que, no âmbito da TBS, norma e transgressão são de caráter discursivo, isto é, são inerentes ao próprio discurso. Portanto, não representam ideologias, crenças ou comportamentos, que são exteriores à língua.

Os encadeamentos argumentativos podem ser formalizados, sob um modo geral, por meio da expressão A CON B, em que A e B são os segmentos constitutivos do encadeamento (podem estar acompanhados de uma negação ou não) e CON é o conector (DC ou PT). A expressão A CON B é denominada aspecto argumentativo. Assim, o encadeamento o preço da TV está baixo, portanto vou comprá-la pode ser traduzido pelo aspecto preço baixo DC comprar. Esse aspecto também constitui o sentido de outros encadeamentos como: se o preço estiver baixo, vou comprar a TV; ou até mesmo: comprei esta TV porque o preço estava baixo.

Diferentes encadeamentos podem ser construídos a partir da alternância dos conectores e acréscimo da negação, como se vê abaixo:

(i) O preço está baixo, portanto vou comprar (preço baixo DC comprar);

(ii) O preço está baixo, no entanto não vou comprar (preço baixo PT neg-comprar);

(iii) O preço não está baixo, portanto não vou comprar (negpreço baixo DC neg-comprar);

(iv) O preço não está baixo, no entanto vou comprar (neg-preço baixo PT comprar). 
Os quatro encadeamentos/aspectos acima são diferentes perspectivas de um mesmo bloco semântico, o que articula preço baixo a comprar.

Os aspectos normativos e transgressivos podem ser ligados a uma entidade linguística de dois modos: externo ou interno. A argumentação externa (AE) de uma entidade relaciona-se aos discursos que podem preceder ou seguir-se a uma entidade, em que a própria expressão linguística constitui um dos segmentos do encadeamento. É "a pluralidade dos aspectos constitutivos de seu sentido na língua, e que estão ligados a ela de modo externo" (DUCROT, 2002, p. 9). Exemplificando, a AE de preço baixo pode ser preço baixo DC comprar ou preço baixo PT neg-comprar. A AE pode dar-se à direita da expressão, como acabamos de citar, ou à esquerda: aumento de oferta DC preço baixo.

A argumentação interna (AI) é relativa aos encadeamentos que parafraseiam a entidade ou são muito próximos a ela (DUCROT, 2002), ou seja, a expressão não é constitutiva dos segmentos. Ducrot apresenta a $\mathrm{AI}$ de prudente a partir da ideia de que, se alguém é prudente, então toma precaução diante do perigo, como sendo perigo DC precaução.

De forma semelhante, estabelece-se argumentação externa ao enunciado. Uma AE possível de João éprudente poderia ser Pedro é prudente DC não lhe ocorrerá nada de mal. Também é possível estabelecer-se argumentação interna ao enunciado. A AI de João é prudente resulta em perigo DC precaução. Os blocos semânticos construídos a partir dos enunciados de um discurso, seja por meio de $\mathrm{AE}$ ou de $\mathrm{AI}$, permitem que se explicite sua estrutura argumentativa, ou seja, o modo como a argumentação do discurso é produzida.

Os quatro aspectos de um bloco semântico, tal como vimos acima, podem ser organizados de tal modo que evidenciem relações entre si. Como existe um elo de interdependência semântica entre os segmentos A e B de um aspecto argumentativo, esses segmentos podem formar oito possibilidades de encadeamentos, por meio da alternância dos conectores e a presença da negação. Esses oito aspectos dividem-se em dois blocos de quatro aspectos, em que a relação entre A e B é a mesma dentro dos quatro aspectos de cada bloco semântico. Por exemplo, os seguintes quatro aspectos formam um bloco semântico BS1: $A D C B$; $A$ PT neg- $B$; neg- $A$ DC neg- $B$ e neg- $A$ PT $B$. Por outro lado, esses segmentos podem relacionar-se de outra maneira, gerando outro conjunto que forma o bloco BS2: $A D C$ neg- $B ; A P T B$; neg- $A D C$ $B$; e neg- $A$ PT neg- $B$.

Os aspectos pertencentes a cada bloco estabelecem, entre si, relações discursivas, denominadas conversas, recíprocas e transpostas (CAREL; DUCROT, 2005, p. 40). São conversos os aspectos que se distinguem pela troca dos conectores e a negação do segundo segmento; são recíprocos aqueles em que são mantidos os conectores e ambos os segmentos são negados; por fim são transpostos aqueles em que há alternância dos conectores e negação do primeiro segmento.

Desse modo, são conversos os aspectos:

$A D C B$ e $A$ PT neg- $B$, neg- $A D C$ neg- $B$ e neg- $A$ PT $B$.

São recíprocos:

$$
\begin{aligned}
& A D C B \text { e neg- } A D C \text { neg- } B, \\
& A P T \text { neg- } B \text { e neg- } A \text { PT } B .
\end{aligned}
$$

Por último, são transpostos:

neg- $A$ DC neg- $B$ e $A$ PT neg- $B$, $A D C B$ e neg- $A$ PT $B$.

Por meio da relação entre BS1 e BS2, notamos que constituem blocos semânticos contrários. A contrariedade é bem marcada se forem comparados, por exemplo, os aspectos em DC, respectivamente, dos blocos BS1 e BS2:

(BS1) A DC B

(BS2) A DC neg-B

Entre ambos há manutenção do primeiro segmento e do conector, mas o segundo segmento é negado em (BS2), resultando em novo sentido, por exemplo: o preço está baixo, portanto não vou comprar (preço baixo DC negcomprar), uma possibilidade de argumentação para quem desconfia da qualidade de produtos com preço reduzido.

Conforme nossa proposta para este trabalho, focalizamos a atenção em uma das relações discursivas entre os aspectos: a conversão. A conversão tem uma particularidade em seu funcionamento, como mostraremos adiante: além de negar uma argumentação, serve como uma etapa para o locutor propor um novo bloco semântico.

\section{A relação de conversão}

Vimos que a relação de conversão se dá entre os aspectos $A D C B$ e $A P T$ neg- $B$, bem como entre neg- $A$ $D C$ neg- $B$ e neg- $A$ PT $B$, isto é, entre conversos, há manutenção do segmento suporte e negação do aporte, com alternância do conector.

De acordo com Ducrot (CAREL; DUCROT, 2005, p. 55), a relação de conversão corresponde à ideia de negação, que pode ser expressa assim: $[A D C B]$ é falso; é [A PT neg-B] (e vice-versa). Revela uma oposição entre os aspectos. A relação entre conversos é exemplificada com a descrição dos adjetivos prudente e imprudente, em 
que o primeiro teria como argumentação interna perigo $D C$ precaução e o segundo perigo $P T$ neg-precaução. Assim, prudente e imprudente podem ser descritos argumentativamente por meio de aspectos conversos, em que um é a negação do outro.

De posse do que desenvolvemos até aqui, passamos à análise de um discurso, a crônica $O$ líder natural, na qual os conceitos da ADL/TBS serão aplicados visando o cumprimento de nossos objetivos: (i) Descrever o sentido dos discursos por meio de aspectos argumentativos; (ii) Descrever e explicar a relação de conversão entre discursos; e (iii) Analisar as atitudes do locutor quando responde a um discurso do tipo $A$ portanto $B$ com o seu converso $A$ no entanto não- $B$.

\section{O líder natural (VERISSIMO, 2008, p. 79)}

Um avião cai nos Andes. Ou nos Alpes? Nos Andes, nos Andes. Enfim, um avião cai no topo nevado de uma montanha. Todos os seus ocupantes sobrevivem à queda, mas como o socorro custa a chegar, e abandonar o abrigo dos destroços do avião para enfrentar as nevascas e ir procurar ajuda significaria morte certa, os sete - são sete - vêem-se diante do seguinte problema: como permanecer vivos até serem resgatados.

Têm água da neve mas não têm comida, depois que acabar o amendoim. O que fazer?

Os dias passam, o socorro não vem, e cresce entre os sete a certeza de que serão obrigados a recorrer ao canibalismo. Um deles terá de morrer para que os outros se alimentem. Mas quem deve morrer? Qual o critério para escolher o sacrificado?

- Deve ser o mais velho entre nós - opina um jovem. - Um que já viveu bastante, e cujo sacrifício beneficiará os que ainda terão uma vida pela frente, se formos salvos.

- Não esqueçam - diz o mais velho entre eles - que a carne dos idosos é mais dura. E, também, que os mais velhos são mais filosóficos. Desconfio que, se o socorro não vier e nosso fim se revelar inevitável, precisaremos mais de filosofia do que de carne.

- Devemos matar e comer o mais fraco entre nós - diz um musculoso. - Não só será o que oferecerá menor resistência, como a sua carne será provavelmente mais tenra.

- Epa - diz o aparentemente mais fraco de todos. - Onde estamos? A lei do mais forte não pode imperar entre pessoas civilizadas. Proponho um sorteio. Quem perder será o sacrificado.

Nestas ocasiões, sempre aparece um líder natural, alguém com senso prático e superioridade intelectual, que se impõe aos demais. É o que acontece. O líder natural se manifesta:
- Devemos repudiar qualquer tipo de solução que agrida a moral, como a de sacrificar o mais velho só por ser o mais velho, ou a ética, como a dos fortes subjugarem os fracos. Também devemos evitar qualquer tipo de imposição alheia a uma decisão humana, como a da pura sorte no caso de um sorteio. Somos seres racionais, capazes de decidir seu destino racionalmente, e democraticamente.

E propõe:

- Todos devemos nos sacrificar, de forma equânime. É a única solução ética, a única solução moral, a única digna de homens decentes. Em vez de um de nós morrer para alimentar os outros, todos devem dar uma parte do seu corpo para ser comida. E para que a igualdade seja completa, a parte sacrificada do corpo de cada um deve ser a mesma. O braço direito, que faz falta a todos na mesma proporção.

Apesar de alguns protestos, todos acabam aceitando a proposta racional.

Afinal, são homens decentes. E a argumentação do líder natural, de sacrifícios iguais para homens iguais, é irrespondível. Semanas depois, os destroços do avião são localizados e uma turma de resgate descobre seis homens vivos no seu interior. Cinco sem o braço direito, um - o mais musculoso - com os dois braços. E o esqueleto de um sétimo homem, o líder natural, sob cujas ordens cada um tinha cortado o braço direito do outro, até chegar a sua vez de cortar o braço direito do musculoso, quando se revelara que ele era o único canhoto do grupo, e todos tinham caído em cima dele. E cuja carne os mantivera vivos até chegar o socorro. Significando, acho eu, que o importante não é o discurso, é quem discursa.

\section{Análise do discurso}

Vamos agora agrupar as argumentações realizadas por meio de aspectos conversos presentes no discurso, para que possamos descrevê-las e explicá-las quanto ao sentido construído e quanto à atitude tomada pelo locutor ao escolher essa forma de argumentação.

$\mathrm{O}$ primeiro conjunto de conversos refere-se ao discurso do jovem, ao indicar o mais velho para o sacrifício (ser velho DC ser sacrificado), e ao discurso deste último ao defender-se (ser velho PT neg-ser sacrificado). De fato, o velho não nega explicitamente a argumentação do jovem, mas também não refuta ser velho. No entanto, apresenta argumentos que irão dar um novo significado a velho, que são: ter carne dura DC neg-ser apropriado para alimentação e ter mais experiência de vida DC ser mais dado a reflexões. Essas argumentações suportam um novo sentido para velho, ser velho DC neg-ser sacrificado, contrário ao sentido defendido pelo jovem. Logo, o velho opõe-se à argumentação do jovem por meio de seu aspecto 
converso e em seguida passa a defender um novo bloco semântico para escapar da indicação. Assim:

- ser velho DC ser sacrificado (assumido pelo jovem);

- ser velho PT neg-ser sacrificado (assumido pelo velho), converso ao primeiro;

- ser velho DC neg-ser sacrificado (assumido pelo velho), aspecto do bloco semântico contrário ao defendido pelo jovem, ser velho DC ser sacrificado.

$\mathrm{O}$ conjunto Conversos $2 \mathrm{diz}$ respeito à defesa do fraco (ser fraco PT neg-ser sacrificado) contra a indicação feita pelo passageiro mais forte (ser fraco DC ser sacrificado). Como o personagem velho, esse também não nega ser fraco, por isso identificamos a conversão entre os aspectos. Semelhantemente à defesa do velho, o jovem argumenta para poder defender o ponto de vista contrário ao do musculoso. Alega que "A lei do mais forte não pode imperar entre pessoas civilizadas" (ser um grupo civilizado DC neg-aplicar a lei do mais forte) e então deixa implícita sua defesa (ser fraco DC neg-ser sacrificado). Sintetizamos dessa forma:

- ser fraco DC ser sacrificado (assumido pelo forte);

- ser fraco PT neg-ser sacrificado (assumido pelo fraco).

- ser fraco DC neg-ser sacrificado (assumido pelo fraco, aspecto de bloco semântico contrário ao proposto pelo personagem mais forte).

O terceiro conjunto de conversos relaciona-se ao discurso do líder. Ao declarar-se contra as argumentações dos outros passageiros (tomar critérios contrários à moral, à ética e à decisão humana DC tomar critérios não racionais), ele relaciona os aspectos conversos: ser racional $P T$ neg-decidir racionalmente, atribuído à perspectiva dos sobreviventes, e ser racional DC decidir racionalmente, assumido pelo líder. A seguir, defende uma proposta racional, que tem seu sentido representado por serem homens iguais DC sacrificarem-se igualmente. Assim:

- ser racional PT neg-decidir racionalmente (rejeitado pelo líder, assimilado aos sobreviventes);

- ser racional DC decidir racionalmente (assumido pelo líder).

Por fim, o conjunto Conversos 4 esclarece o desfecho da história. Os passageiros aceitaram a argumentação do líder (serem homens iguais DC sacrificarem-se igualmente) e procederam com os cortes dos braços direitos, até perceberem que o líder era canhoto. Ante a descoberta, colocamos serem homens iguais PT neg-sacrificaremse igualmente, aspecto converso ao do líder, como o sentido causador da revolta dos passageiros. Além disso, colocamos também os conversos fazer discurso racional e justo DC ser uma pessoa respeitável e fazer discurso racional e justo PT neg-ser uma pessoa respeitável como representativos da imagem do líder construída por ele mesmo, o aspecto normativo, e a imagem dele construída pelos passageiros após a revelação de ser canhoto, o transgressivo. O líder é morto por ter transgredido a norma por ele mesmo proposta. Interessante observar que, distintamente dos outros casos envolvendo a conversão, nesse, especificamente, não houve a defesa de novo bloco como justificativa da transgressão. Aqui, o rompimento da norma não foi perdoado. Em síntese:

- serem homens iguais PT neg-sacrificarem-se igualmente (atribuído aos passageiros).

- serem homens iguais DC sacrificarem-se igualmente (assumido pelo líder);

- fazer discurso racional e justo DC ser uma pessoa respeitável (imagem que o líder faz de si);

- fazer discurso racional e justo PT neg-ser uma pessoa respeitável (imagem construída pelo líder após a revelação).

Basicamente encontramos no discurso analisado formas de excluir-se de um grupo, no caso, dos indicados ao sacrifício. As defesas do velho e do fraco opuseram-se às acusações (por meio de aspectos conversos a elas) e buscaram argumentos para as transgressões construindo novos blocos semânticos. Assim escaparam de serem sacrificados. O caso do líder foi inusitado. Ele opôs-se aos outros (também por um aspecto converso), propôs novo bloco semântico (a proposta racional), mas sua atitude foi entendida como transgredindo a norma por ele mesmo levantada, e por tal atitude foi condenado.

Ao analisarmos os aspectos conversos, notaremos que o locutor de um concorda com o locutor do outro quanto ao segmento suporte, já que é mantido. Entretanto, o aporte não é o mesmo, e então há possibilidade de discussão devido à oposição de pontos de vista. Se um locutor disser Maria é prudente (perigo DC precaução) e o outro rebater com Não é verdade, Maria é imprudente (perigo PT neg-precaução) abre-se a possibilidade do debate, já que são duas opiniões opostas.

Porém, em termos de discurso, de língua em uso, não basta a oposição de opiniões. Ao locutor que se opõe a outro será pedido que argumente por sua vez, e esclareça seu posicionamento, ou o diálogo será rompido. Em outras palavras, o locutor deverá apresentar outra argumentação (um novo bloco semântico) que sustente, ou explique, a sua oposição.

Entre argumentos conversos há confronto entre uma norma e a transgressão dessa norma. Como exemplo, o locutor de ser velho PT neg-ser sacrificado expressa a insuficiência do segmento suporte para o aporte na argumentação de ser velho DC ser sacrificado. O locutor velho considera que aquele suporte não é único para o 
aporte, ou, ao menos, não é apropriado, a seu modo de ver. Em termos da TBS, o locutor velho discorda da escolha feita pelo locutor jovem. A contestação da continuação do segmento suporte pode levar à refutação do bloco semântico pela construção de uma nova norma (de fato, um novo bloco). Salientamos que ambos os aspectos (em DC e em PT) pertencem ao mesmo bloco, mas a rejeição da norma, em uma situação discursiva, quer dizer, no uso da língua, pode levar ao questionamento do bloco como um todo e à proposição de novo sentido.

\section{Considerações finais}

Buscamos, com este trabalho, descrever e explicar as atitudes de um locutor ao posicionar-se frente a outro discurso em relação de conversão, bem como investigar os sentidos construídos pelas relações estabelecidas entre esses discursos, sob o viés da Teoria da Argumentação na Língua, na sua fase da Teoria dos Blocos Semânticos.

Trabalhamos com a análise de uma crônica e descrevemos as argumentações construídas pelos locutores e como essas interagiam com outros discursos ali presentes. Também identificamos os sentidos que as relações entre aspectos podem assumir no discurso. A argumentação por aspectos conversos mostrou a oposição a outro discurso pela transgressão à norma e pela negação do segundo segmento, o aporte. Pela conversão, o locutor nega a norma. Contudo, a refutação pelo aspecto converso a outro não se faz suficiente na língua em uso, pois é como se simplesmente disséssemos "não" em resposta a uma afirmação. As análises confirmaram que, na interação entre locutores, após a contestação por um converso, geralmente há a proposição de um novo bloco semântico que apoia a objeção de um ponto de vista. Caso não haja a apresentação desse novo bloco, o diálogo pode ser rompido. Apesar de termos chegado a essas respostas, sabemos que este trabalho apenas inicia uma linha de investigação: a relação entre discursos pela ADL/TBS. Não temos pretensão de impor conclusões definitivas, pois sabemos da importância de pesquisas futuras para a confirmação ou refutação dos resultados.

\section{Referências}

CAREL, Marion; DUCROT, Oswald. La semántica argumentativa - una Introducción a la Teoría de los Bloques Semánticos. Buenos Aires: Colihue, 2005.

CAREL, Marion; DUCROT, Oswald. Descrição argumentativa e descrição polifônica: o caso da negação. Letras de Hoje, Porto Alegre, v. 43, n. 1, mar. 2008.

DUCROT, Oswald. Enunciação. Enciclopédia Einaudi. Lisboa: Imprensa Nacional, Casa da Moeda, 1984.

DUCROT, Oswald. O dizer e o dito. Campinas: Pontes, 1987.

DUCROT, Oswald. Argumentação e "topoi” argumentativos. In: GUIMARÃES, Eduardo (Org.). História e sentido na linguagem. Campinas: Pontes, 1989.

DUCROT, Oswald. Polifonía y argumentación - Conferencias del Seminario Teoría de la Argumentación y Análisis del Discurso. Cali: Universidad del Valle, 1990.

DUCROT, Oswald. Os internalizadores. Letras de Hoje, Porto Alegre, v. 37, n. 3, p. 7-26, set. 2002.

DUCROT, Oswald. Argumentação retórica e argumentação linguística. Letras de Hoje, Porto Alegre, v. 44, n. 1, jan./mar. 2009.

SAUSSURE, Ferdinand de. Escritos de Linguística Geral. Tradução Carlos Augusto Leuba Salum e Ana Lucia Franco. São Paulo: Cultrix, 2004.

VERISSIMO, Luis Fernando. Mais comédias para ler na escola. Rio de Janeiro: Objetiva, 2008.

Recebido: 30 de novembro de 2014

Aprovado: 28 de janeiro de 2015

Contato: claudio.delanoy@pucrs.br 